\title{
COVID-19 SEROPREVALENCE AMONG ROYAL THAI ARMY PERSONNEL IN BANGKOK METROPOLITAN AREA FROM JULY-SEPTEMBER 2020
}

Nakarin Sansanayudh, Khunakorn Kana, Nitiya Asavikool, Sumalee Phajan, Maneerat Somsri, Surachai Rusamegevanon, Thanainit Chotanaphuti

\section{Armed Forces Research Institute of Medical Sciences, Royal Thai Army Medical Department, Bangkok, Thailand}

\begin{abstract}
Background: COVID-19 is an ongoing pandemic that causes millions of deaths worldwide. Seroprevalence studies play a crucial role in identifying asymptomatic infection and providing the true prevalence of COVID-19 in the community. However, no COVID-19 seroprevalence in Thailand has been reported before.

Objective: The study aimed to measure the prevalence of the SARS-CoV-2 antibody among army personnel residing in the Bangkok Metropolitan Area.

Methods: All army personnel receiving health checkups from 1 July - 30 September 2020 were invited to participate in the study after providing informed consent. The seroprevalence was conducted using leftover serum without additional venipuncture. The screening conducted using the Rapid test by Wondfo ${ }^{\circledR}$. When a screening test was positive, a confirmation test would be performed using ELISA by EuroImmun ${ }^{\circledR}$. In case of a positive ELISA confirmation test result, the COVID-19 investigation team would be activated and deployed.
\end{abstract}

Results: In all, 6,651 army personnel participated in this study. The age of participants ranged from 20-60 years with mean age of 40.5 \pm 12.02 . Most participants were male (85.5\%). The rapid screening test using Wondfo ${ }^{\circ}$ was positive in 41 cases $(0.61 \%)$. The confirmation test using ELISA yielded a positive result in 1 subject $(0.015 \%)$. That person was a known case of COVID-19 infection, who received a full course of treatment and was confirmed to have negative RT-PCR before being discharged from the hospital a few weeks earlier.

Conclusion: This was the first large scale seroprevalence surveillance of COVID-19 in Thailand. Our study revealed no new detectable case of asymptomatic COVID-19 infection in the Bangkok Metropolitan Area.

Keywords: COVID-19 infection, Military personnel, Bangkok Metropolitan Area

J Southeast Asian Med Res 2020; 4(2) : 67-74

http://www.jseamed.org

Correspondence to:

Sansanayudh N, Armed Forces Research Institute of Medical Sciences, Royal Thai Army Medical

Department, Thailand

E-mail: dr_nakarin@hotmail.com

Received: 02 October 2020

Revised: 03 November 2020

Accepted: 04 December 2020 


\section{Introduction}

Coronavirus disease 2019 (COVID 19) is a pandemic caused by severe respiratory syndrome coronavirus (SARS-CoV)-2. The first case was reported in Wuhan, Hubei Province in PR China in December 2019. ${ }^{(1,2)}$ Shortly after, it spread to countries in Europe and the US. ${ }^{(3-5)}$ The World Health Organization (WHO) declared COVID 19 a public health emergency of international concern (PHEIC) 30 January 2020. On 11 March 2020, WHO declared COVID 19 a global pandemic. At the time of this manuscript, more than 73 million persons had contracted this disease with more than 1.6 million deaths in 235 countries.

COVID-19 infection is acute without any carrier status. Symptoms usually begin with nonspecific syndromes, including fever, dry cough and fatigue, and multiple systems may be involved. After the onset of illness, the symptoms are somehow mild and the median time to first hospital admission is 7.0 days. ${ }^{(6)}$ During this period, the patient could transmit SAR-CoV-2 to other people. Furthermore, many infected patients are asymptomatic. This group of patients is usually not tested for COVID 19 infection and may potentially be a source of infection. To achieve effective control of this COVID 19 pandemic, active surveillance of asymptomatic infection is also necessary.

The Armed Forces Research Institute of Medical Science (ARFIMS) has the duty of providing annual health checkup services for Military Personnel in Bangkok and the Metropolitan Area. More than 15,000 army personnel complete health questionnaires, receive a physical examination, blood test, and chest X-RAY every year. Health education is usually given to all army personnel during the annual checkup event. Therefore, this checkup service is an ideal platform for conducting an additional epidemiological study on the COVID-19 endemic. The study aimed to conduct a seroprevalence survey among army personnel residing in the Bangkok Metropolitan Area.

\section{Methods}

This constituted a cross-sectional study to identify the prevalence of seropositive COVID-19 cases in the Bangkok Metropolitan Area. All enlisted army units were contacted and the study was approved by the commander of each unit. The liaison officers of each army unit were explained the details of the study. All army personnel receiving health check-ups from 1 July to 30 September 2020 were invited to participate in the study after providing informed consent. Each personnel went through the usual process of health check-up programs, including physical examination and blood tests, except for answering a few additionalquestions regarding the risk of COVID-19 infection. The seroprevalence was conducted using leftover serum without additional venipuncture. The screening was conducted using the Rapid test by Wondfo $®$. When the screening test result was positive, a confirmation test would be performed using ELISA by EuroImmune ${ }^{\circledR}$. In the case of a positive ELISA confirmation test result, the COVID-19 investigation team would be activated and deployed. Thorough disease investigation was undertaken and the standard surveillance protocol was followed. The flow diagram of the study is shown in Figure 1. 


\section{Collect blood samples of personnel participating in RTA}

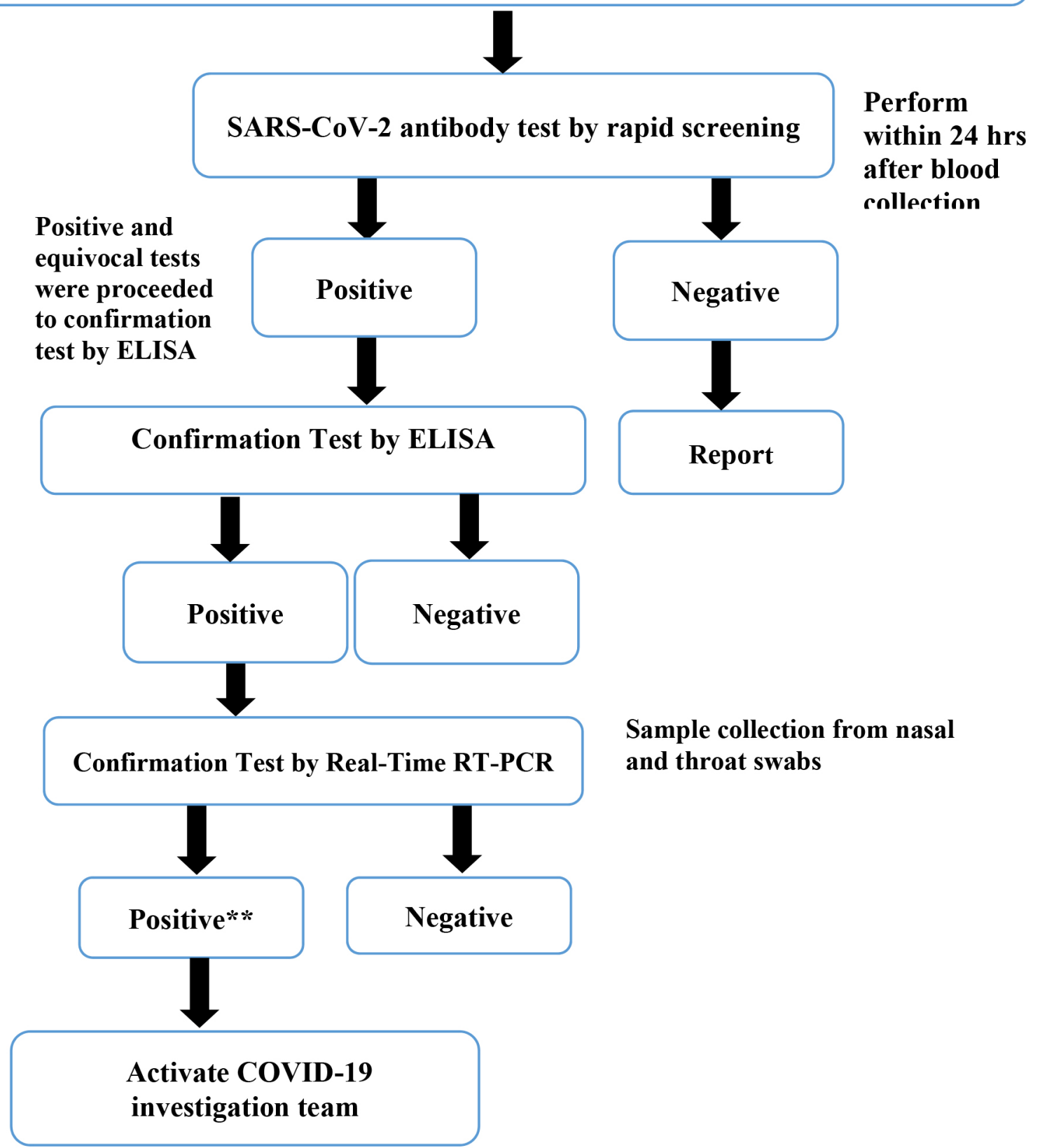

Figure 1. Flow diagram of the study 
Table 1. Demographic data of enrolled participants

\begin{tabular}{|c|c|c|c|c|}
\hline \multicolumn{2}{|c|}{ Characteristics } & \multirow[t]{2}{*}{$\mathbf{n}$} & \multirow{2}{*}{$\begin{array}{l}\text { Mean (SD) } \\
40.5(12.02)\end{array}$} & \multirow[t]{2}{*}{ Percentage } \\
\hline Age & & & & \\
\hline Sex & Male & 5,684 & & 85.5 \\
\hline & Female & 967 & & 14.5 \\
\hline \multirow[t]{4}{*}{ Rank } & $\begin{array}{l}\text { Non-commissioned } \\
\text { officer }\end{array}$ & 4,301 & & 64.7 \\
\hline & Commissioned officer & 1,583 & & 23.8 \\
\hline & Civilian employees & 747 & & 11.2 \\
\hline & Others & 20 & & 0.3 \\
\hline BMI & & 6,651 & $25.04(3.9)$ & \\
\hline
\end{tabular}

\section{Results}

In all, 6,651 army personnel were included in this study. The age of participants was from 20 to 60 years with mean age of $40.5 \pm 12.02$. The baseline demographic data are shown in Table 1. $(\mathrm{n}=6,651)$

The location of army units participating in this study is depicted in Figure 2. The rapid screening test using Wondfo ${ }^{\circledR}$ was positive in 41 cases $(0.61 \%)$. The confirmation test by ELISA yield positive results in one subject $(0.015 \%)$. Table 2 reveals the result of a positive rapid screening and ELISA classified by unit.

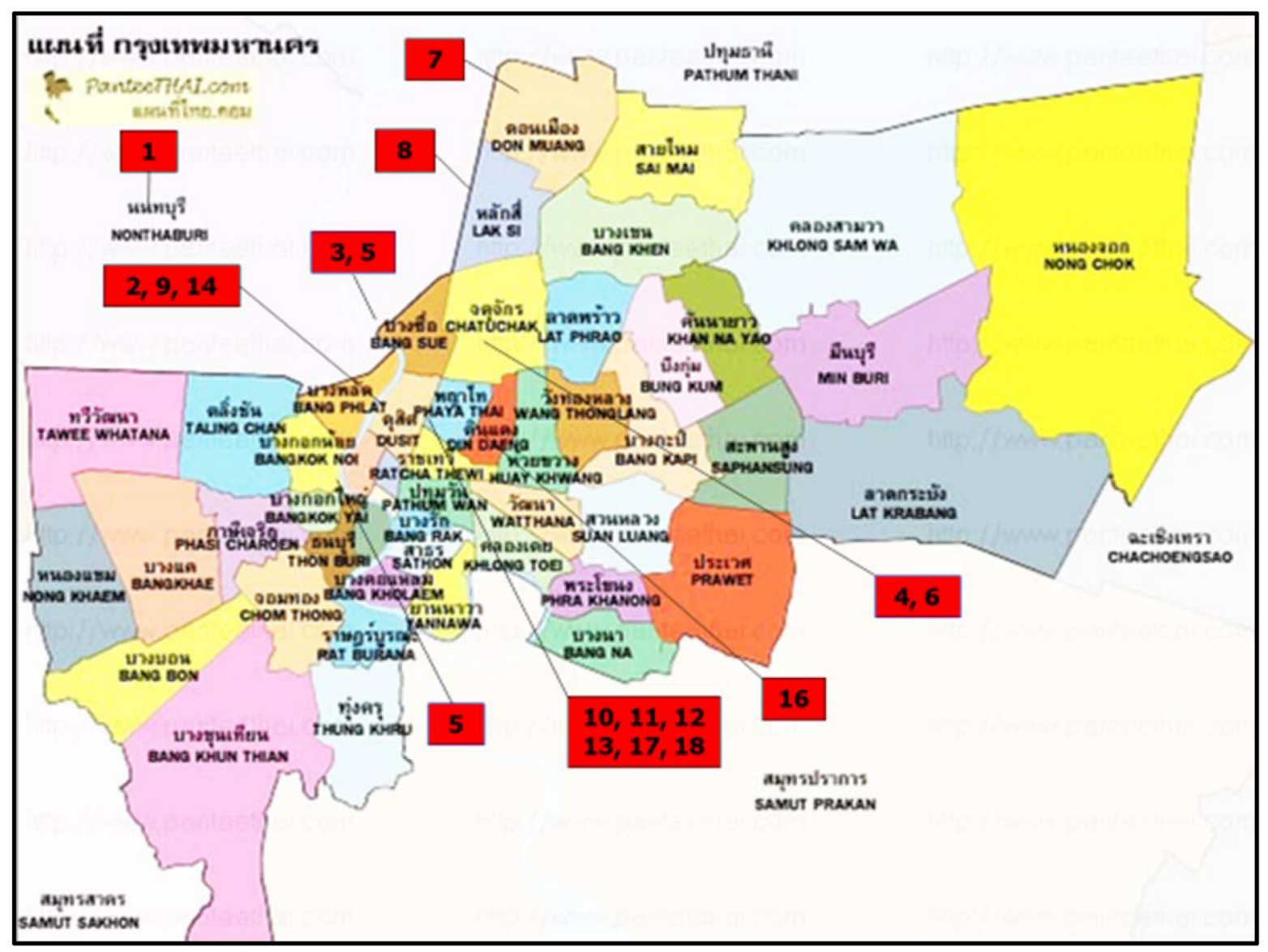

Figure 2. Map of Bangkok Metropolitan Area and location of army units participating in this study 
Table 2. Results of the rapid screening test and ELISA in each army unit

\begin{tabular}{|c|c|c|c|}
\hline $\begin{array}{c}\text { Unit } \\
\text { number }\end{array}$ & $\begin{array}{l}\text { Number of } \\
\text { personnel }\end{array}$ & $\begin{array}{l}\text { Positive by rapid } \\
\text { screening }\end{array}$ & $\begin{array}{c}\text { Positive } \\
\text { by ELISA }\end{array}$ \\
\hline 1 & 1,474 & 8 & 0 \\
\hline 2 & 392 & 4 & 0 \\
\hline 3 & 130 & 0 & 0 \\
\hline 4 & 329 & 0 & 0 \\
\hline 5 & 429 & 2 & 0 \\
\hline 6 & 126 & 1 & 0 \\
\hline 7 & 439 & 0 & 0 \\
\hline 8 & 458 & 0 & 0 \\
\hline 9 & 603 & 4 & 0 \\
\hline 10 & 290 & 3 & 1 (Ig G) \\
\hline 11 & 93 & 0 & 0 \\
\hline 12 & 249 & 3 & 0 \\
\hline 13 & 125 & 1 & 0 \\
\hline 14 & 163 & 4 & 0 \\
\hline 15 & 328 & 4 & 0 \\
\hline 16 & 581 & 5 & 0 \\
\hline 17 & 198 & 2 & 0 \\
\hline \multirow[t]{2}{*}{18} & 244 & 0 & 0 \\
\hline & 6,651 & 41 & 1 \\
\hline
\end{tabular}

After confirming a positive blood sample using the ELISA test, an AFRIMS investigation team was deployed. The investigation revealed that the person with a positive SAR CoV-2 antibody was a 20-year-old man who was a known case of COVID-19 infection residing with his father and mother. Both he and his mother contracted the disease from his father who was part of the Thai-boxing cluster of epidemics. All three were treated at Pharmongkutklao Hospital for 7 days from 28 March 28 to 6 April 2020, and were discharged from the hospital after their clinical symptoms resolved and their RT-PCR results were negative. All their neighbors and possible contact persons had already received an RT-PCR test when this family was admitted to the hospital and all tests yielded negative results. Therefore, no additional action was taken.

\section{Discussion}

Severe acute respiratory syndrome coronavirus (SARS-CoV)-2 has infected more than 46 million people worldwide leading to nearly 1.2 million deaths and an unprecedented impact on economics, society, and life style of people globally. Thailand is among the first countries to report COVID 19 outside China when a traveler from Wuhan was confirmed to have SAR-CoV-2 infection 8 January 2020.(7) The number of cases in Thailand remained low from January to February followed by a big outbreak in March. A state of emergency was declared 26 March. A nationwide curfew was declared from 3 April to 15 June 2020. However, the state of emergency has not been waived until now. With the rapid response, prompt policy and effective intervention from the government together with great cooperation from Thai citizens, the situation of 
COVID-19 infection in Thailand was maintained under control. The strong network of Village Health Volunteers played important role in screening, detecting and active surveilling of possible infected cases as well as educating local communities and implementing health campaigns. Thailand is one of the two countries that have been chosen by the WHO as successful models to be featured in a documentary about handling and stemming the spread of COVID 19. The current situation of Thailand revealed total cases of 3,784 with 59 mortality cases. Bangkok is the city with the highest number of COVID-19 cases.

Because COVID-19 could present with mild symptoms or could be asymptomatic, a concern existed that the incidence of the actual infection in Thailand might be underreported. No active surveillance using antibody detecting in Thailand has been reported before. Related studies in many countries have revealed that seroprevalence for COVID-19 varied from and 3.2 to $3.8 \%$ in Wuhan, $4.65 \%$ in LA County, $5 \%$ in Spain and $7.3 \%$ in Stockholm. ${ }^{(8-12)}$

This study was the first report of a large-scale seroprevalence survey in Thailand. In this study, we chose Bangkok and the Metropolitan Area because it constituted the area with the greatest incidence of COVID-19 infection in the country and potentially the highest chance of asymptomatic infection. We conducted a seroprevalence survey as an annex to an established program of annual health checkup services. The integration of the study in a solid and well-established platform was the key success of this study. We received great cooperation from both commanders of the units and army personnel. Only a few questions were added to the regular health questionnaire and no additional venipuncture was required.

The screening was conducted using Wondfo ${ }^{\circledR}$ rapid test. Wondfo ${ }^{\circledR}$ was the first officially approved antibody test for SAR-CoV-2 in China. The total antibody test indicated a sensitivity and specificity of Wondfo ${ }^{\circledR}$ reported by the company product description to be $86.43 \%$ (95\% CI = $82.51-89.58 \%)$ and $99.57 \%(95 \% \mathrm{CI}=97.63-$ $99.52 \%)$, respectively(13). The sensitivity of Wondfo ${ }^{\circledR}$ varied according to the time between the onset of symptoms and the antibody test. One related publication revealed a sensitivity of
$52.2 \%(95 \% \mathrm{CI}=37.0-67.1 \%)$ when Wondfo ${ }^{\circledR}$ was used within two weeks of the onset. The sensitivity increased to $91.3 \%(95 \% \mathrm{CI}=$ $72.0-91.9 \%$ ) when the test was performed from days 15 to 21 . The sensitivity further increased to $100 \%(95 \% \mathrm{CI}=88-100 \%)$ when tested among patients after three weeks of symptom onset, while the specificity in this study was reported to be $100 \%(95 \% \mathrm{CI}=69.2-100 \%)$ (14). Similar findings were reported by Serrano et al. (15). The sensitivity of Wondfo $\AA$ in this study was $66.7 \%$ (95\% CI $=46-83.5 \%), 97.4 \%$ (95\% CI $=86.5$ to $99.9 \%)$, and $98 \%(95 \% \mathrm{CI}=89.4$ to $99.9 \%$ ) when the test was performed days 1 to 7 , days 8 to 14 and days 15 to 28 , respectively. The specificity was $95.2 \%$ to $100 \%$. The related publication also revealed low sensitivity when Wondfo ${ }^{\circledR}$ was performed using capillary blood (55\%) but high sensitivity when a serum sample was used (96\%)(16). In our study, we used the leftover serum and all equivocal test results from Wondfo ${ }^{\circledR}$ were initially classified as positive and were proceeded to be confirmed using ELISA test to ensure the highest possible sensitivity.

Among 6,651 blood samples obtained, 41 samples $(0.61 \%)$ yielded a positive screening test result (including equivocal test results). ELISA by EuroImmun ${ }^{\circledR}$ was used as a confirmation test. Euroimmun ${ }^{\circledR}$ is a standard antibody test that received both FDA EAU approval and CE mark. It has been used as a confirmation test for many rapid tests in many related publications. Euroimmun ${ }^{\circledR}$ had the sensitivity and specificity of $90 \%(95 \% \mathrm{CI}=74.4$ to $96.5 \%)$ and $100 \%$ $(95 \% \mathrm{CI}=95.4$ to $100 \%)$ according to FDA EUA website. ${ }^{(13)}$ Charlton et al. reported the sensitivity of Euroimmun ${ }^{\circledR}$ to be $83 \%(95 \% \mathrm{CI}=67-93 \%)$. The sensitivity increased with a longer time from the onset of symptoms. The sensitivity of Euroimmun ${ }^{\circledR}$ was $76 \%(95 \%$ CI $=53-92 \%)$ when the test was conducted at days 0 to 14 after the onset of the symptoms and increased to $82 \%$ (95\% CI $=48-98 \%)$ when conducted from day 15 to 21 . The sensitivity was $100 \%(95 \% \mathrm{CI}=$ $68-100 \%$ ) after day 21 of symptoms onset, while specificity in this study was $100 \%(95 \% \mathrm{CI}=$ 93-100\%). ${ }^{(17)}$

Among 41 positive (and equivocal) screening tests, one case $(0.015 \%)$ was confirmed to have antibodies to COVID 19. That person was a 
known case of COVID-19 infection who had already received full treatment and was fully recovered from the infection. There has been no confirmation of asymptomatic infection from this active seroprevalence surveillance. There might be a question of whether the number of blood samples tested in our study was sufficient to reflect the true prevalence of infection in the Bangkok Metropolitan Area. According to Hilborne et al., when the size of the population is large, the number of required samples for a seroprevalence study is nearly identical and not dependent on the increase in the number of the total population. Hilbourne et al. proposed the maximum number of screening tests required for seroprevalence to be 2,377 tests which was far less than the number of blood tests in our survey. ${ }^{(18)}$

\section{Conclusion}

This constituted the first large scale seroprevalence surveillance of COVID-19 in Thailand. Our study revealed no new detectable cases of asymptomatic COVID-19 infection in the Bangkok Metropolitan Area. Most people in Bangkok have no immunity against SAR-CoV-2 and are vulnerable to the infection. The proposed approach to achieve herd immunity in Thailand is very unlikely to be successful and is unethical in this circumstance.

\section{References}

1. Czernin J. Dr. Li Wenliang and the Time of COVID-19. J Nucl Med 2020; 61: 625.

2. Li X, Cui W, Zhang F. Who Was the First Doctor to Report the COVID-19 Outbreak in Wuhan, China? J Nucl Med 2020; 61: 782-3.

3. Bernard Stoecklin S, Rolland P, Silue Y, Mailles A, Campese C, Simondon A, et al. First cases of coronavirus disease 2019 (COVID-19) in France: surveillance, investigations and control measures, January 2020. Euro Surveill 2020;25(6).

4. Holshue ML, DeBolt C, Lindquist S, Lofy KH, Wiesman J, Bruce H, et al. First Case of 2019 Novel Coronavirus in the United States. N Engl J Med 2020; 382: 929-36.

5. Remuzzi A, Remuzzi G. COVID-19 and Italy: what next? Lancet 2020; 395: 1225-8.
6. Li Q, Guan X, Wu P, Wang X, Zhou L, Tong $\mathrm{Y}$, et al. Early Transmission Dynamics in Wuhan, China, of NovelCoronavirus-Infected Pneumonia. N Engl J Med 2020; 382: 1199-207.

7. Okada P, Buathong R, Phuygun S, Thanadachakul T, Parnmen S, Wongboot W, et al. Early transmission patterns of coronavirus disease 2019 (COVID-19) in travellers from Wuhan to Thailand, January 2020. Euro Surveill 2020; 25(8).

8. Ng DL, Goldgof GM, Shy BR, Levine AG, Balcerek J, Bapat SP, et al. SARS-CoV-2 seroprevalence and neutralizing activity in donor and patient blood. Nat Commun 2020; 11: 4698

9. Pollan M, Perez-Gomez B, Pastor-Barriuso R, Oteo J, Hernan MA, Perez-Olmeda M, et al. Prevalence of SARS-CoV-2 in Spain (ENE-COVID): a nationwide, populationbased seroepidemiological study. Lancet 2020; 396: 535-44.

10. Sood N, Simon P, Ebner P, Eichner D, Reynolds J, Bendavid E, et al. Seroprevalence of SARS-CoV-2-Specific Antibodies Among Adults in Los Angeles County, California, on April 10-11, 2020. JAMA 2020; 323: 2425-7.

11. Stringhini S, Wisniak A, Piumatti G, Azman AS, Lauer SA, Baysson H, et al. Seroprevalence of anti-SARS-CoV-2 IgG antibodies in Geneva, Switzerland (SEROCoV-POP): a population-based study. Lancet 2020; 396: 313-9.

12. Xu X, Sun J, Nie S, Li H, Kong Y, Liang M, et al. Author Correction: Seroprevalence of immunoglobulin $\mathrm{M}$ and $\mathrm{G}$ antibodies against SARS-CoV-2 in China. Nat Med 2020; 26: 1494.

13. 2020 [Available from: https://www.bilcare. com/SARS-CoV-2\%20Antibody $\% 20$ Test $\%$ 20(Lateral\% 20Flow\%20Method).pdf

14. Wu JL, Tseng WP, Lin CH, Lee TF, Chung $\mathrm{MY}$, Huang $\mathrm{CH}$, et al. Four point-of-care lateral flow immunoassays for diagnosis of COVID-19 and for assessing dynamics of antibody responses to SARS-CoV-2. J Infect 2020; 81: 435-42. 
15. Serrano MM, Rodriguez DN, Palop NT, Arenas RO, Cordoba MM, Mochon MDO, et al. Comparison of commercial lateral flow immunoassays and ELISA for SARS-CoV-2 antibody detection. J Clin Virol 2020; 129: 104529.

16. Santos VAD, Rafael MM, Sabino EC, Duarte A. Sensitivity of the Wondfo One Step COVID-19 test using serum samples. Clinics (Sao Paulo) 2020; 75: e2013.
17. Charlton CL, Kanji JN, Johal K, Bailey A, Plitt SS, MacDonald C, et al. Evaluation of Six Commercial Mid- to High-Volume Antibody and Six Point-of-Care Lateral Flow Assays for Detection of SARS-CoV-2 Antibodies. J Clin Microbiol 2020; 58: e01361-20.

18. Hilborne LH, Wagner Z, Cabreros I, Brook RH. Linking Statistics With Testing Policy to Manage COVID-19 in the Community. Am J Clin Pathol 2020; 154: 142-8. 